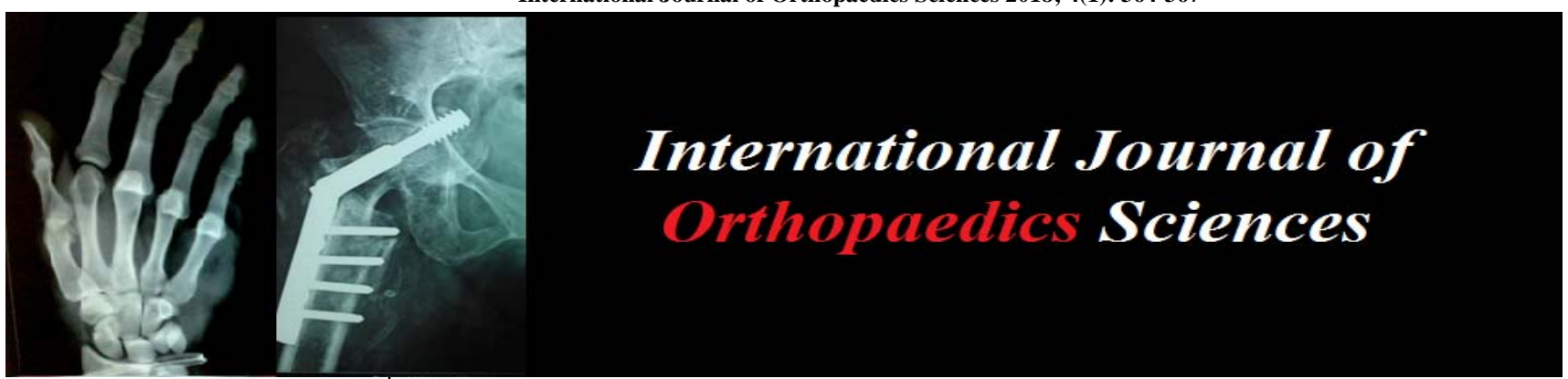

ISSN: $2395-1958$

IJOS 2018; 4(1): 364-367

(C) 2018 IJOS

www.orthopaper.com

Received: 01-11-2017

Accepted: 02-12-2017

Dr. Prakash Wali

Associate Professor, Belagavi

Institute of medical sciences,

Belagavi, Karnataka, India

Dr. Santosh Mared

Senior Resident, Belagavi

Institute of medical sciences,

Belagavi, Karnataka, India
Correspondence

Dr. Prakash Wali

Associate Professor, Belagavi

Institute of medical sciences,

Belagavi, Karnataka, India.

\section{A retrospective clinical study of volar Barton fractures using t- Elli's plate and locking distal end radius plate and screws}

\author{
Dr. Prakash Wali, Dr. Santosh Mared \\ DOI: https://doi.org/10.22271/ortho.2018.v4.i1f.51
}

\section{Abstract}

Aim To evaluate the functional and radiological results of treating unstable volar Barton's fractures of the distal radius with the T-buttress plate and locking plate

Methods: This was a retrospective study at our hospital. We used open reduction and internal fixation with a 3.5mmT-buttress plates and lockingplate in volarly displaced, intraarticular fractures of the distal radius which were displaced volarly. The volar tilt, radial length, articular step-off and intraarticular gap between fragments were improved after surgery. We included 40 patients, comprising 37 men and 3 women with a mean age of 31 years (range from 20-62 years).12 patients were treated with locking plate whereas rest of 28 patients were treated with T butress plate and scerws. Preoperative, postoperative, and final follow-up radiographs were compared. The time to initiation of active range of motion was determined. Final follow-up range of motion and complications were reported. Mean follow-up time after injury was 6 months.

Results: At final functional assessment, the scores of 18 patients were excellent, 5 patients good, 5 patients fair in patients treated with T butress plate and screws. 7 patients excellent, 4 good, 1 fair in patients treated with locking plate and screws according to a criteria described by Gartland and Werley. No non-union or infection occurred. No difference in the improvement was seen in patients treated with locking plate and screws.

Conclusion: Treatment of volar Barton's fractures of the distal radius with a 3.5mm T-buttress plate or locking plate leads to satisfactory results, provided the operative technique is carefully performed to prevent complications. Rigid fixation of the fracture is important for good outcome no matter the type of implant used.

Keywords: Volar Barton's fracture, open reduction, internal fixation, T-buttress plate, locking compression plate

\section{Introduction}

Barton's fracture, named after the American surgeon John Rhea Barton ${ }^{[1]}$ is a fracture of the distal end of the radius that involves the dorsal or volar rim and extends into the intra-articular region. Such intra-articular fractures are uncommon, and they are usually associated with either low or high-energy trauma. They constitute only $1.3 \%$ of the distal radius fractures. Various forms of treatment have been described in literature ${ }^{[2]}$. These include closed reduction and plaster application, percutaneous pinning, external fixation, open reduction and internal fixation (ORIF) with Kirschner wires, and ORIF with a buttress plate or locking plate and screws. These options are differentiated based on their ability to reinforce and stabilize the three columns of the distal radius and ulna. Closed reduction is usually easy to achieve but difficult to maintain leading to Intra- ${ }^{-}$articular and extra- ${ }^{-}$articular malalignment which leads to various complications such as posttraumatic osteoarthrosis, decreased grip strength and endurance, as well as limited motion, and carpal instability. The epidemiological profile has changed from the times of Colle's fracture to present date due to increased life expectancy. The age specific incidence of the distal radius fracture, as stated by various authors, has been ranged from 9 to 100 per 10,000 per year ${ }^{[3,4]}$. In spite of various new advances close reduction and cast immobilization has been the mainstay of treatment of these fractures but malunion of fracture and subluxation/dislocation of distal radioulnar joint resulting in poor 
functional and cosmetic results is the usual outcome [5, 6] Recently, the volar locked plate osteosynthesis is considered as the "gold standard" in treatment of unstable distal radius fractures ${ }^{[7]}$.

In the early 1950s, James Ellis from England started using a specially designed $\mathrm{T}^{-}$plate to buttress the small marginal fragment in volar Barton's fractures. In 1970s, the AO group designed plates specifically for the treatment of distal radius fractures.

Open reduction and volar plating ensures more consistent correction of displacement and maintenance of reduction. Conservative treatment is usually unsuccessful, and it is also fraught with complications, such as early osteoarthrosis, deformity, subluxation, and instability. Several studies have been reported on the effectiveness of surgical treatment using $\mathrm{T}$ butress plate and locking plate with excellent to good results. This study was undertaken in our hospital to know the efficacy of the two implants.

\section{Materials and methods}

From 2005 to 2016, a total of 40 cases of volar Barton's fracture were operated on by ORIF. 40 patients, comprising 37 men and 3 women with a mean age of 41 years (range from 20-62 years).12 patients were treated with locking plate whereas rest of 28 patients were treated with $\mathrm{T}$ butress plate and screws. Mechanism of injury was high-energy trauma (i.e. a motor vehicle accident) in 12 cases and fall in 28 cases. Associated injuries included hip fractures, femoral fractures in 5 patients. The fractures were classified according to the $\mathrm{AO}$ classification. All of the fractures were type-B3 injuries; that is, the volar aspect of the distal articular surface of the radius was involved while the dorsal aspect of rim intact.

The majority of the cases were operated on within one week of the injury using general anaesthesia or brachial block.

\section{Surgical technique}

A pneumatic tourniquet was used in all cases in order to provide bloodless field during surgery. The fracture site was exposed through the distal part of the volar approach of Henry ${ }^{[8]}$. The distal radius was exposed along the flexor carpi radialis tendon. After release of the pronator quadratus muscle from its radial insertion, the fracture site and palmar surface of the distal radius were exposed. Fracture is reduced in anatomical position Fracture reduction was verified with the image intensifier focussing on restoration of articular congruity. Provisional Kirschner wires were used occasionally. Next, the length of the radius is adjusted for proper ulnar variance by pushing the plate distally to restore the distal radio-ulnar congruity and fixation of the fracture fragments was performed by a $3.5 \mathrm{~mm}$ T-buttress plate or locking plate with small fragment screws. Intraop-retively radiographs were assessed by measuring the volar angulation and ulnar angulation of the distal-end radius. Volar and ulnar angles were angles of the articular surface of the distal end of the radius in lateral and anteroposterior views between the sagittal and coronal planes, respectively. Iliac crest bone graft was performed for 1 patient. The pronator quadratus was repaired with 2-0 absorbable sutures.

\section{Postoperative treatment}

A above-elbow plaster splint was applied for 4 weeks; passive and active range-of-motion exercises started during after the first check xray at 4 weeks after confirming the status of the fracture. Patients were followed up initially at 4-week intervals up to 12 weeks, If the result of the fracture and the function of the wrist was satisfactory then final $\mathrm{x}$-ray and follow up was done at 6 months.

\section{Results}

The average follow-up period was 6 months (range 1-12 months). All fractures were healed in a mean period of 8 weeks (range 6-10 weeks). There was no non-union or wound infection in this study. No breakage of plates was observed. Postoperative radiographs were evaluated. Postoperative radiographic assessment revealed a mean volar angle of $8 \%$ (range, -2.0-14.0) and a mean ulnar angle of 20.7(range, 10.0-28.0). Average final wrist range of motion was $55 \pm 10$ degrees extension (range 45 to 80 degrees) and 60 \pm 15 degrees flexion (range 50 to 90 degrees). Average final forearm range of motion was $80 \pm 15$ degrees pronation (range 30 to 100) and $90 \pm 5$ degrees supination (range 80 to 100 degrees). At final functional assessment, the scores of 18 patients were excellent, 5 patients good, 5 patients fair in patients treated with $\mathrm{T}$ butress plate and screws. 7 patients excellent, 4 good, 1 fair in patients treated with locking plate and screws according to a criteria described by Gartland and Werley. No non-union or infection occurred. No difference in the improvement was seen in patients treated with locking plate and screws.

\section{Discussion}

Distal end radius fractures are the most frequently seen upper extremity fractures. As far as the treatments of these fractures are concerned, it is one of the most challenging types. The main objective of treatment is to re-establish anatomic integrity and function. It has undergone changes owing to the advances in technology. Improved imaging methods provide better understanding of fractures and elucidation of the effects of the injury type on fracture formation and factors that lead to instability. Volar Barton's fractures are not common injuries; they constitute only $1.3 \%$ of distal-end radius fractures [9-13]. Various forms of treatment have been described. They include closed reduction and plaster application, percutaneous pinning, external fixation, ORIF with Kirschner wires, and ORIF with a buttress plate.

Closed reduction is usually easy to achieve but difficult to maintain. In an experimental study of the pathomechanics of volar Barton's fractures, King ${ }^{[10]}$ observed that the stability of a reduction depended on an intact radiocarpal ligament and concluded that these fractures should be immobilised, keeping the wrist in palmar flexion. Although King reported no poor results, all patients had mild pain, weakness, and some loss of motion at follow-up.

As with all intraarticular fractures, anatomical reduction and internal fixation are the ultimate goals of treatment for these injuries. This point has been very well emphasised by the few authors in their studies on Barton's fractures ${ }^{[14,16]}$.

In our study, the distal radial fracture was more common in the 3rd and 5th decade with an average of 41 years. It is comparable with other similar studies ${ }^{[17,18]}$ done earlier. Type B3 fractures were included which met the criteria of fracture of volar barton ${ }^{[19]}$. Of the 40 patients 12 patients were treated with locking plate whereas rest of 28 patients were treated with $\mathrm{T}$ butress plate and screws. $83 \%$ inpatients treated with $\mathrm{T}$ butress plate and screws achieved excellent to good results whereas $91 \%$ achieved the same in patients treated with locking plate and screws. Bone grafting was done in 1patient where in process of achieving radial length a gap was created in the metaphyseal region following distraction. Our results are consistent with those studies that supported the 
effectiveness of ORIF ${ }^{[14-16]}$.

In our study not much of difference were noted in results treated with two different implants. This would suggest that the fractures treated are in the upper limb where the deforming forces as in lower limb fractures are not encountered. Hence we would like to conclude the choice of implants does not make difference while fixation of volar barton. The final result depends on acheving the articular congruity and mainting it till union of the fracture.

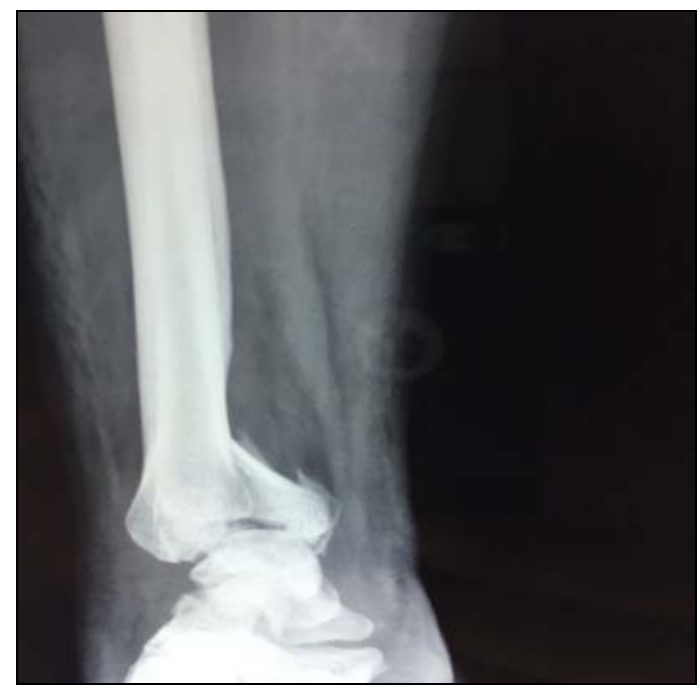

Lateral--pre operative $\mathrm{x}$-ray before t elli's plate

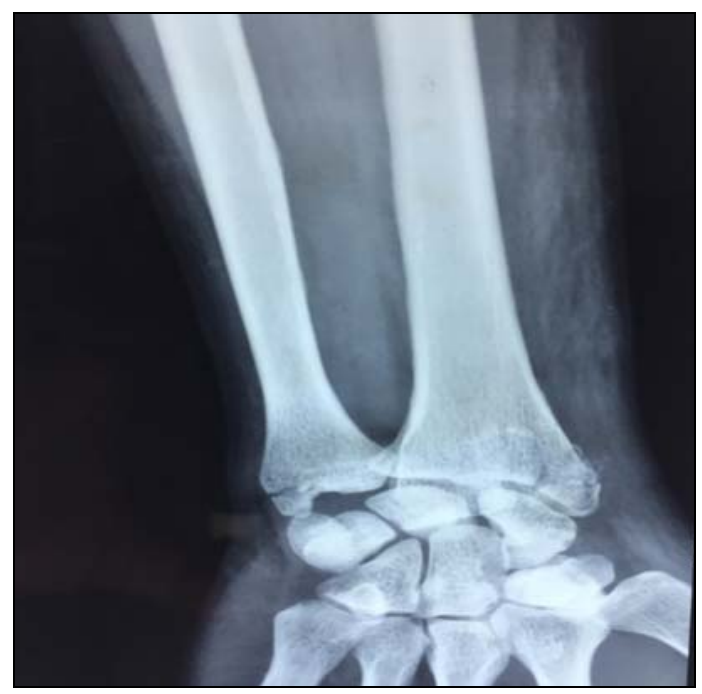

Ap-pre operative x-ray before t elli's plate

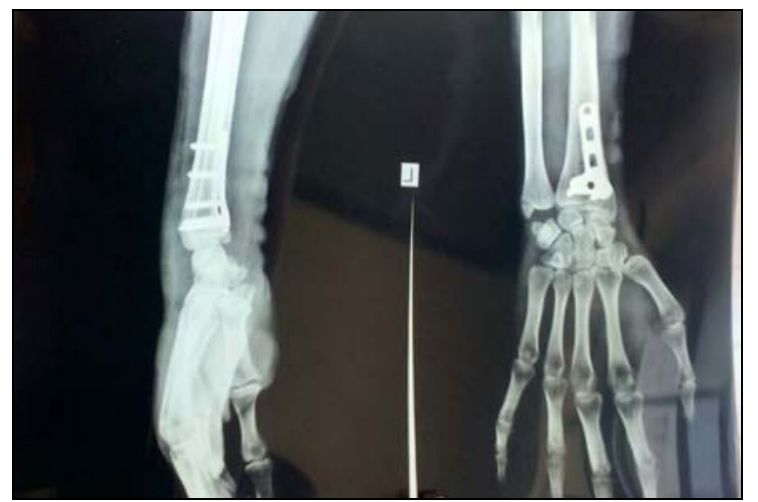

Post op x-ray after t elli's plate and screws

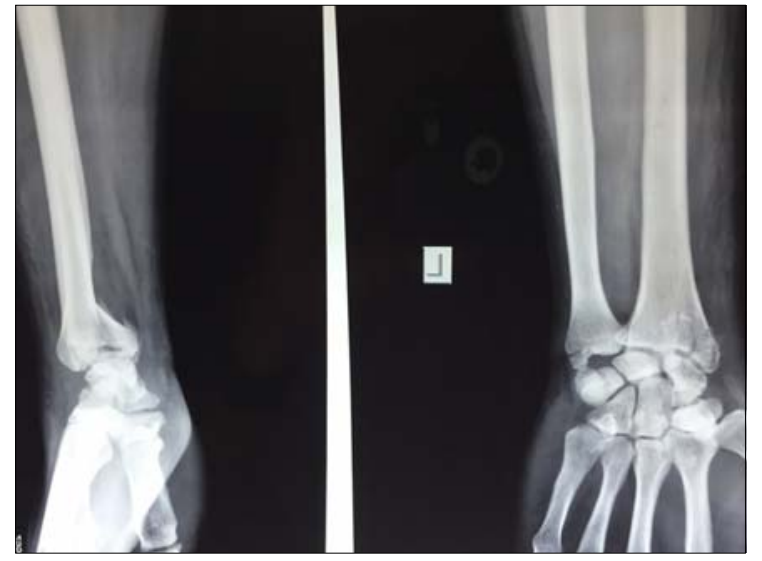

Ap and lateral-pre operative $\mathrm{x}$-ray before locking plate and screws

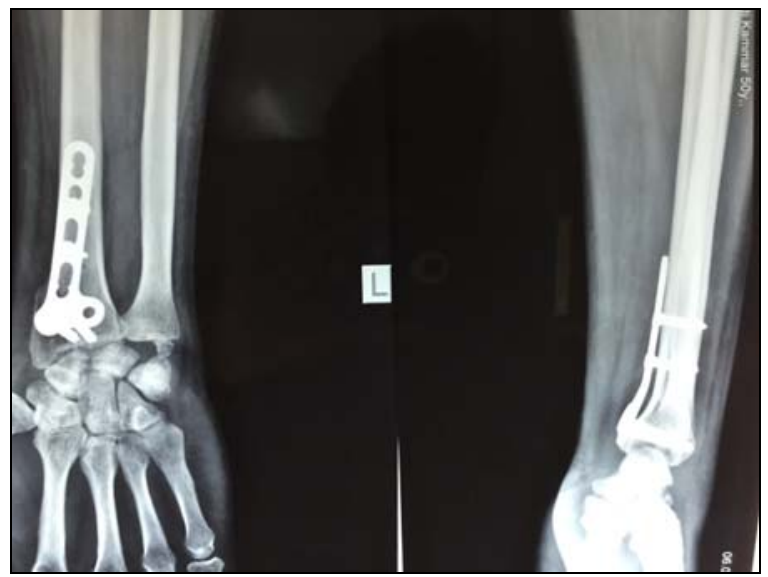

Ap and lateral-post operative x-ray after locking plate and screws

\section{References}

1. Barton JR. Views and treatment of an important injury to the wrist. Philadelphia Med Exam. 1838; 1:365-8.

2. Brogren E, Petranek M, Atroshi I, Wright TW, Horodyski M, Smith DW. Functional outcome of unstable distal radius fractures: ORIF with a volar fixedangle tine plate versus external fixation. J Hand Surg Am. 2005; 30(2):289-299.

3. Brogren E, Petranek M, Atroshi I. Incidence and characteristics of distal radius fractures in a southern Swedish region. BMC Musculoskelet Disord. 2007; 8:48.

4. Thompson PW, Taylor J, Dawson A. The annual incidence and seasonal variation of fractures of the distal radius in men and women over 25 years in Dorset, UK. Injury. 2004; 35(5):462-6.

5. Westphal T, Piatek S, Schubert S, Winckler S. Outcome after surgery of distal radius fractures: no differences between external fixation and ORIF. Arch Orthop Trauma Surg. 2005; 125(8):507-514.

6. Kreder HJ, Hanel DP, Agel J et al. Indirect reduction and percutaneous fixation versus open reduction and internal fixation for displaced intra-articular fractures of the distal radius: a randomised, controlled trial. J Bone Joint Surg Br. 2005; 87(6):829-836.

7. Stevenson I, Carnegie CA, Christie EM, Kumar K, Jhonstone AJ. Displaced distal radius fracture treated using volar locking plate: maintenance of normal anatomy. J of Trauma. 2009; 67(3):612-6.

8. Henry AK. Extensile exposures. 2nd ed. Baltimore: Williams and Wilkins, 1957, 67.

9. Pattee GA, Thompson GH. Anterior and posterior 
marginal fracture-dislocations of the distal radius. An analysis of the results of treatment. Clin Orthop. 1988; 231:183-95.

10. King RE. Barton's fracture-dislocation of the wrist. Curr Pract Orthop Surg, 1975; 6:133-44.

11. Thompson GH, Grant TT. Barton's fractures-reverse Barton's fractures. Confusing eponyms. Clin Orthop, 1977; 122:210-21.

12. Bohler L. Treatment of fractures. Bristol, England: John Wright \& Sons, 1943.

13. De Oliveira JC. Barton's fractures. J Bone Joint Surg Am. 1973; 55:586-94.

14. Jupiter JB, Fernandez DL, Toh CL, Fellman T, Ring D. Operative treatment of volar intra-articular fractures of the distal end of the radius. J Bone Joint Surg Am. 1996; 78:1817-28.

15. Zoubos AB, Babis GC, Korres DS, Pantazopoulos T. Surgical treatment of 35 volar Barton fractures. No need for routine decompression of the median nerve. Acta Orthop Scand Suppl. 1997; 275:65-8.

16. Mehara AK, Rastogi S, Bhan S, Dave PK. Classification and treatment of volar Barton fractures. Injury. 1993; 24:55-9.

17. Kiliç A, Kabukçuoglu Y, Ozkaya U, Gül M, Sökücü S, Ozdogan U. Volar locking plate fixation of unstable distal radius fractures. Acta Orthop Traumatol Turc. 2009; 43:303-8.

18. Othman AY. Fixation of dorsally displaced distal radius fractures with volar plate. J Trauma. 2009; 66:1416-20.

19. Muller ME, Nazarian S, Koch P, Schatzker J. The comprehensive classification of fractures of long bones. New York: Springer, 2000. 